\title{
IMPACTOS DAS EMPRESAS ESTRANGEIRAS SOBRE O COMÉRCIO EXTERIOR BRASILEIRO: EVIDÊNCIAS DA DÉCADA DE 901
}

\author{
Mariano F. Laplane ${ }^{2}$ \\ Fernanda De Negri ${ }^{3}$
}

\section{INTRODUÇÃO}

Historicamente, as empresas transnacionais têm desempenhado um papel importante na economia brasileira. O modelo desenvolvimentista baseado no tripé Estado, capital estrangeiro e capital privado nacional já concedia um papel extremamente relevante aos investimentos estrangeiros, particularmente nos setores de bens de capital e bens de consumo duráveis. Segundo estudo da Cepal, no final dos anos 70 as empresas transnacionais (ETS) respondiam por 32\% da produção industrial do país e, em 1977, cerca de $11 \%$ do capital acumulado na economia brasileira e $23 \%$ do capital da indústria de transformação era fruto de investimentos estrangeiros (CEPAL,1998). Em função da significativa importância das ETS na estrutura produtiva brasileira, diversos foram os estudos realizados na tentativa de qualificar a sua contribuição, particularmente no período de industrialização.

Nos anos 90, a crescente internacionalização da economia brasileira e a fragilidade de seu balanço de transações correntes no período recente, evidenciada pelas dificuldades em compatibilizar crescimento econômico sustentado e balança

1 Uma versão preliminar deste artigo foi publicada como Texto para Discussão do IPEA No 1002, Brasília, IPEA, dezembro de 2003.

2 Núcleo de Economia Industrial e da Tecnologia-NEIT, Instituto de Economia-Unicamp.<mlaplane@eco.unicamp.br>

3 Núcleo de Economia Industrial e da Tecnologia-NEIT, Instituto de Economia-Unicamp.<fdenegri@eco.unicamp.br> 
comercial equilibrada, reacenderam o debate acerca da possível contribuição das empresas estrangeiras para o desempenho comercial do país.

Diversos fatores são recorrentemente citados na literatura como determinantes do desempenho comercial diferenciado das empresas estrangeiras em relação às nacionais. Em primeiro lugar estão os fatores diretamente relacionados à atuação multinacional dessas empresas, tais como o acesso a mercados e canais de comercialização por meio das filiais localizadas em outros países. Em segundo lugar, fatores como produtividade, tamanho e tecnologia tendem a ser citados como vantagens competitivas potenciais das empresas estrangeiras em relação às nacionais. Por fỉm, a concentração das empresas estrangeiras em setores mais avançados tecnologicamente e/ou com graus de inserção comercial significativamente diferentes do restante da economia também, é um fator constantemente lembrado nas explicações do desempenho comercial diferenciado das empresas estrangeiras.

Nos anos 90, esses fatores alimentaram expectativas de que o rápido aumento dos fluxos de investimento direto estrangeiro (IDE) e a maior presença de empresas estrangeiras redundaria em melhor desempenho da balança comercial brasileira. Para outros autores essas expectativas eram exageradamente otimistas e desconsideravam características importantes do tipo de IDE e do comportamento das ETS no Brasil. As limitações dos dados disponíveis e evidências parciais contraditórias alimentaram um longo debate sobre o impacto efetivo da presença das empresas estrangeiras na balança comercial. Este trabalho se propõe a sintetizar a evolução do debate e oferecer, a partir dos resultados de uma análise em painel dos micro-dados dos fluxos de comércio das empresas estrangeiras e nacionais, evidências mais conclusivas sobre o tema.

\section{ETS E COMÉRCIO EXTERIOR: O DEBATE DOS ANOS 90}

No início da década, alguns autores argumentavam que os investimentos estrangeiros, além de constituírem uma fonte adicional de financiamento do balanço de pagamentos por meio da conta de capital, contribuiriam também para a melhora do desempenho comercial do país. Atribuía-se essa expectativa ao fato de que as empresas estrangeiras teriam acesso a canais de comercialização e a mercados ainda não explorados pela economia brasileira, e também à maior competitividade das estrangeiras visà-vis às empresas locais.

Esta parecia ser a expectativa de Fritsch e Franco (1989) quando ressaltavam o papel dos investimentos diretos e das empresas multinacionais (EMNS) para a redução da restrição externa. Por um lado, por meio do aporte 
direto de capital e, indiretamente, pela contribuição das empresas estrangeiras ao crescimento do saldo comercial. Segundo eles:

as EMN's ou suas associações com empresas nacionais que garantam a transferência dos ativos intangíveis relevantes podem dar uma dupla contribuição ao crescimento das exportações em termos de acesso tanto à tecnologia quanto a mercados (FRITSCH; FRANCO, 1989, p. 21).

Na segunda metade dos anos 90 vários estudos foram realizados com a intenção de verificar os impactos efetivos da atuação das empresas estrangeiras no comércio exterior brasileiro. As evidências empíricas sugeriram a conveniência de rever algumas das expectativas otimistas à respeito da contribuição dessas empresas ao saldo comercial.

Uma dessas evidências, de grande relevância para o desempenho comercial do país, é a concentração dos investimentos diretos em segmentos orientados, principalmente, para o mercado interno e/ou regional, ou seja, os investimentos estrangeiros na década foram essencialmente market seeking. Laplane e Sarti (1997), ao analisar as características dos fluxos de investimento direto para a economia brasileira nos anos 90, apontaram algumas tendências nesse sentido.

Em primeiro lugar, veio a constatação de que, no início da década, o fluxo de IDE "esteve fortemente associado a um processo de racionalização e modernização da estrutura produtiva" (p. 148) 4 e que este processo trazia consigo um elevado componente de importação de bens de capital e produtos intermediários. Assim, os autores sugeriam que uma parcela dos déficits comerciais de alguns setores da economia brasileira entre 1994 e 1996, particularmente o complexo automotriz, a indústria eletroeletrônica e o setor de produtos farmacêuticos, poderiam ser explicados pelas estratégias de modernização das empresas estrangeiras. A constatação de que os déficits comerciais brasileiros vinham crescendo no comércio com os países-sede destas empresas reforçava essa intuição:

Ou seja, a hipótese é de que, em grande parte, o aumento de importações globais e setoriais se deve ao processo de redução nos índices de nacionalização dos bens finais, como resultado das estratégias de especialização adotadas pelas EE, que têm terceirizado

4 Ver também, Bielschowsky e Stumpo (1996). 


\begin{abstract}
algumas atividades produtivas e/ou transferido a compra de componentes para seus fornecedores estrangeiros em termos mundiais (global sourcing), em detrimento de fornecedores locais (LAPLANE; SARTI, 1997, p. 155)
\end{abstract}

Em segundo lugar, após 1994, o fluxo de IDE esteve ligado à recuperação da demanda doméstica promovida pela estabilização, indicando que o dinamismo do mercado interno constituía o principal fator de atração desse investimento. Nesse sentido, os autores analisaram os projetos de investimento de 79 empresas estrangeiras e constataram a importância do mercado interno e do Mercosul como determinantes desses investimentos.

Portanto, tanto a concentração do IDE na produção de bens para o mercado interno e regional, quanto a propensão a importar produtos intermediários e bens de capital enfraqueceria a hipótese de uma contribuição positiva das ETS ao saldo comercial brasileiro.

Complementando a análise precedente, Laplane e Sarti (1999) analisaram informações sobre o comércio exterior de 74 empresas estrangeiras nos anos de 1989, 1992 e 1997 (tabela 1), fortalecendo algumas das tendências apontadas no trabalho anterior. Em primeiro lugar, observava-se que as empresas superavitárias eram aquelas que atuavam em setores intensivos em recursos naturais (filiais resource seeking). Por outro lado, as filiais que atuavam nos setores de bens de consumo duráveis e de equipamentos (filiais market seeking) eram deficitárias.

Os coeficientes de comércio intrafirma foram estimados a partir do volume de comércio da filial com o país-sede de sua matriz. A análise desses coeficientes mostrava que o país-sede da matriz atuava mais fortemente como origem das importações das filiais brasileiras do que como destino de suas exportações. O estudo também mostrava a ampliação do coeficiente de comércio interfiliais dessas empresas com o Mercosul que, paralelamente com a redução dos fluxos filial-matriz no mesmo período, ratificavam a "vocação regional das filiais brasileiras".

Outro argumento levantado pelos autores que colocava em dúvida a contribuição das empresas estrangeiras ao desempenho comercial do país dizia respeito à orientação dos investimentos recentes para o setor de serviços, que passou a concentrar a maior parte do capital estrangeiro na economia (LAPLANE e SARTI, 1997; 1999).

Os autores que viam na nova onda de investimentos estrangeiros uma possibilidade concreta de aumento da competitividade internacional do país concentraram seus argumentos, ora na transitoriedade do viés importador dos novos investimentos, ora nos seus impactos sobre a competitividade da indústria. 
Tabela 1- SALDO COMERCIAL E COEFICIENTE DE COMÉRCIO INTRAFIRMA (MATRIZ-FILIAL) PARA EMPRESAS ESTRANGEIRAS SELECIONADAS. 1989, 1992 E 1997.

\begin{tabular}{lccccc}
\hline \multirow{2}{*}{ Setores } & \multicolumn{3}{c}{ Saldo $(\mathbf{1})$} & \multicolumn{2}{c}{ Comércio intrafirma } \\
\cline { 2 - 6 } & $\mathbf{1 9 8 9}$ & $\mathbf{1 9 9 2}$ & $\mathbf{1 9 9 7}$ & $\mathbf{X}$ & $\mathbf{M}$ \\
\cline { 2 - 6 } & 413 & 338 & 977 & 3,99 & 20,93 \\
Alimentos & 1346 & 1470 & -603 & 22,42 & 34,64 \\
Automobilístico & 89 & 361 & 340 & 32,16 & 45,2 \\
Autopeças & -26 & -13 & -804 & 35,73 & 31,04 \\
Eletroeletrônico & -41 & -104 & -341 & $18,42^{*}$ & $28,97 *$ \\
Farmacêutico & 197 & 331 & 440 & 6,84 & 29,76 \\
Fumo & -35 & 60 & -169 & - & - \\
Higiene e limpeza & -58 & -19 & -317 & 27,63 & 50,07 \\
Informática & -26 & -6 & -148 & 15,51 & 22,97 \\
Maq. e equip. elétricos & 299 & 191 & 199 & 22,36 & 82,93 \\
Maq. e equip. mecânicos & 692 & 600 & 497 & 43,15 & 6,62 \\
Mineração & 283 & 261 & 388 & 30,05 & 61,87 \\
Papel e celulose & -183 & -178 & -575 & 18,57 & 48,27 \\
Química & 400 & 569 & 492 & 1,66 & 36,15 \\
Siderurgia/metalurgia & -22 & -115 & -792 & 3,62 & 68,43 \\
Telecomunicações & $\mathbf{3 3 2 9}$ & $\mathbf{3 7 4 6}$ & $\mathbf{- 4 1 6}$ & $\mathbf{1 9 , 4 7}$ & $\mathbf{3 9 , 7 2}$ \\
Total & & & & & \\
\hline
\end{tabular}

FONTE: SECEX. Elaboração NEIT/IE/UNICAMP. Adaptado de Laplane e Sarti (1999).

OBS. (1) Em US\$ milhões. (2) Como porcentagem do comércio total. * Farmacêutico/Hig. e Limpeza.

Barros e Goldenstein (1997), por exemplo, observavam com otimismo o novo ciclo de investimentos estrangeiros argumentando que as mudanças estruturais que estavam acontecendo alterariam as tendências da indústria brasileira no futuro. Para eles, a pressão negativa dos investimentos estrangeiros sobre a balança comercial cessaria no momento da maturação desses investimentos, ao reduzirem-se as importações de bens de capital. Além disso, o crescimento do mercado interno propiciado pela estabilização estaria proporcionando um aumento das escalas de operação da indústria local, o que incentivaria futuramente novos investimentos para produção de componentes, naquele momento importados.

Quanto aos impactos das multinacionais sobre a competitividade da indústria brasileira, Bonelli (1998) argumentava que os investimentos estrangeiros, aliados com a abertura da economia, tiveram um impacto 
importante no substancial crescimento dos indicadores de produtividade observados durante os anos 90.

De fato, parece que as empresas estrangeiras, bem como as nacionais, tiveram que fazer um grande esforço para se ajustar à nova situação de concorrência com os produtos importados. Esse processo de ajustamento contribuiu significativamente para o aumento dos índices de produtividade, salientado por vários autores durante a década. Entretanto, Bielschowsky (1994), a partir de entrevistas com 55 grandes empresas estrangeiras, identificava dois movimentos no processo de ajustamento dessas empresas: a concentração em atividades centrais e a busca por maior eficiência produtiva. Este duplo movimento resultou em um ajustamento baseado, preponderantemente, na redução de pessoal e no aumento das compras de produtos intermediários, tanto interna quanto externamente. Essa constatação apontava para um aumento do coeficiente de importação das empresas estrangeiras a partir da abertura, o que poderia significar uma restrição importante para o desempenho comercial brasileiro durante a década.

Autores como Moreira (1999), entretanto, defendiam que o novo ciclo de investimentos estrangeiros traria uma relação custo-benefício mais vantajosa para o país devido, principalmente, ao rompimento do viés antiexportador do antigo regime de substituição de importações. A partir da análise de dados sobre produtividade, concentração e comércio exterior de uma amostra de cerca de 20 mil firmas nacionais e estrangeiras, o autor concluiu que, em virtude das transformações ocorridas na economia brasileira nesta década, o novo ciclo de investimentos estrangeiros assumia uma característica radicalmente distinta dos ciclos anteriores (anos 60 e70). Em relação ao comércio externo, o autor rebate as análises que verificavam a existência de um viés pró-importação dos investimentos estrangeiros. Sua argumentação se concentrou no fato de que as empresas estrangeiras também poderiam atuar no sentido inverso em virtude do acesso a redes de distribuição, capital e tecnologia, além das externalidades positivas geradas pela presença dessas empresas. Além disso, Moreira procurava salientar que a maior propensão a importar dessas empresas poderia estar relacionada com os setores nos quais atuam, mais intensivos em capital e tecnologia. A partir de exercícios econométricos, o autor constatava que "para um dado setor e para um dado tamanho de firma, as exportações das empresas estrangeiras são, em média, $179 \%$ superiores às nacionais, enquanto no caso das importações essa superioridade chega a 316\%" (MOREIRA, 1999, p. 28).

Em outro estudo, Moreira (2000) demonstrava que as empresas estrangeiras tinham uma probabilidade maior a exportar e, além disso, o valor esperado de suas exportações era $32 \%$ maior do que o valor esperado das 
exportações das empresas nacionais. Neste estudo, o autor não abordava as diferenças existentes entre os dois grupos de firmas em termos de importações. Outras variáveis como receita total, intensidade de capital e de mão-de-obra, salário médio e qualificação do trabalhador, concentração e utilização da capacidade dos setores nos quais as empresas atuavam também foram incluídas no modelo estimado.

Outro exercício no sentido de identificar as diferenças no comportamento comercial de empresas nacionais e estrangeiras foi elaborado - para Argentina, Brasil e Uruguai - em Chudnovsky et al. (2002). Para o caso brasileiro, utilizaram-se informações sobre as 500 maiores empresas, representativas de $49,74 \%$ das exportações e $33,72 \%$ das importações brasileiras.

Neste estudo, os autores observaram um aumento do coeficiente de importação das empresas estrangeiras no Brasil no período 1992-2000 e uma pequena redução nos seus coeficientes de exportação nesse mesmo período. Além disso, constatava-se que, em média, os coeficientes de importação das empresas estrangeiras eram superiores aos das empresas nacionais (tabela 2 ).

A significância destas diferenças foi estimada a partir de um teste de diferenças de médias no qual foram controlados o setor e o tamanho da firma. Os autores estabeleceram que não existiam diferenças significativas

Tabela 2- TESTE DE DIFERENÇA DE MÉDIA ENTRE OS COEFICIENTES DE COMÉRCIO E NA ORIENTAÇÃO DO COMÉRCIO DE EMPRESAS NACIONAIS E ESTRANGEIRAS. BRASIL: 1992, 1997 E 2000.

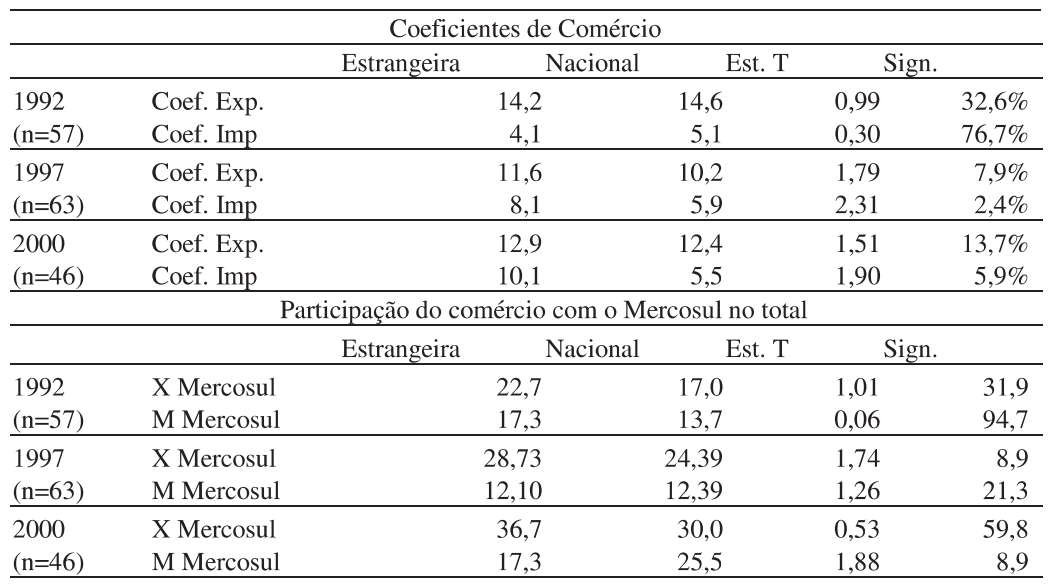

FONTE: Chudnovsky (Org.), 2002. 
nos coeficientes de comércio entre empresas estrangeiras e nacionais em 1992. Em 1997 e 2000, entretanto, embora as diferenças não se mostrassem significativas para os coeficientes de exportação, eram significativas para os coeficientes de importação.

Outro teste realizado pelo estudo diz respeito à existência ou não de uma orientação comercial diferenciada entre empresas nacionais e estrangeiras, para empresas de mesmo tamanho e atuando em um mesmo setor. A tabela 2 mostra que não é possível estabelecer diferenças significativas entre empresas nacionais e estrangeiras no que diz respeito à proporção do seu comércio exterior para o Mercosul.

Novamente, estas evidências contradiziam as expectativas otimistas dos autores que esperavam que a maior internacionalização da economia brasileira resultaria em saldos comerciais mais favoráveis. Para Laplane et al. (2000), estas expectativas eram baseadas em hipóteses muito genéricas a respeito da atuação das empresas transnacionais e desconsideravam as especificidades da atuação das filiais no Brasil. Mesmo entre as filiais presentes no país, não existia homogeneidade quanto aos seus modos de inserção internacional.

Nesse sentido, Hiratuka (2002) procurou elaborar uma tipologia das filiais brasileiras de empresas estrangeiras por meio da comparação de suas diferentes estratégias de inserção externa. $\mathrm{O}$ autor constatou que apenas um tipo de estratégia, denominada de "integração global" e claramente minoritária entre as filiais brasileiras, contribuía para a melhoria quantitativa e qualitativa da balança comercial brasileira. Para ele, "a abertura e a estabilização não foram suficientes para que a orientação ao comércio exterior das filiais brasileiras seguisse de maneira uniforme na direção esperada por aqueles que defendiam o papel preponderante dessas empresas no processo de redução da vulnerabilidade externa da economia brasileira".

A despeito dessas controvérsias, parece ser fato, apontado pela literatura e comprovado empiricamente para o Brasil, que as empresas estrangeiras têm uma maior propensão a se engajar em atividades de comércio do que as nacionais. A esse respeito, Arbache e De Negri (2001) mostraram que o fato de a empresa ser estrangeira aumenta em $700 \%$ sua probabilidade de exportar em comparação com a empresa nacional. Para chegar a essa conclusão, os autores controlaram fatores como tamanho, escolaridade e tempo de emprego dos trabalhadores na firma e setor de atuação. 


\section{BALANÇO E REAVALIAÇÃO DO PROBLEMA A PARTIR DE UMA ANÁLISE DE DADOS EM PAINEL}

O debate anterior traz algumas constatações importantes a respeito do impacto da internacionalização produtiva sobre o desempenho comercial brasileiro. A primeira delas diz respeito ao fato de que as empresas estrangeiras parecem ser, de fato, mais orientadas ao comércio do que as empresas nacionais como, aliás, postula a literatura sobre o tema. Entretanto, parece também existir uma assimetria no que tange às propensões a importar e a exportar. Vários estudos apontam para uma diferença maior nos coeficientes de importação entre os dois grupos de empresas do que nos coeficientes de exportação, ambas diferenças a favor das empresas estrangeiras. No caso específico da comparação entre as 500 maiores empresas, a diferença nos coeficientes de exportação nem chega a ser estatisticamente significativa.

A maior parte dos trabalhos resenhados, quando procura avaliar a influência da origem de capital sobre o desempenho comercial das firmas, leva em consideração fatores como tamanho e setor de atuação. Apenas aqueles estudos que procuram captar a influência dessa variável sobre a probabilidade da firma exportar controlam fatores adicionais.

Entretanto, dado que - e este é um ponto freqüentemente abordado no debate - as empresas estrangeiras possuem diferenças importantes em relação às empresas nacionais, diferenças essas que podem influenciar o seu desempenho comercial, é importante levá-las também em consideração na análise dos fluxos de comércio dessas empresas.

Os fatores citados na literatura que justificam a maior abertura ao comércio exterior das ETs estão relacionados, por um lado, às ligações internacionais das empresas transnacionais em função de sua própria multinacionalidade. Por outro lado, diversos estudos recentes registram a existência de outras diferenças entre empresas nacionais e estrangeiras quanto à produtividade, tecnologia e tamanho. Todos esses fatores são elementos importantes na determinação da competitividade internacional das firmas. Além disso, a inserção setorial diferenciada das empresas estrangeiras também já foi citada como um fator relevante na determinação dos fluxos de comércio destas firmas.

De Negri (2003) procurou analisar as diferenças entre empresas nacionais e estrangeiras na indústria brasileira no período de 1996 a 2000 isolando esses fatores e identificando sua contribuição para o desempenho 
comercial. Para tanto, utilizaram-se informações sobre 53.860 empresas, ${ }^{5}$ responsáveis por cerca de $80 \%$ das exportações e $70 \%$ das importações brasileiras. Entre as empresas analisadas pelo Censo de Capitais Estrangeiros do Banco Central de 1995 e de 2000, 2.132 são estrangeiras. Importante ressaltar que, durante o período, as aquisições e vendas de empresas foram acompanhadas por meio de informações da PIA, o que possibilitou observar as mudanças de nacionalidade existentes no período e identificar o ano de sua ocorrência. Assim, entre as mais de 2000 empresas estrangeiras, aproximadamente 900 permaneceram estrangeiras durante todo o período. As demais, sofreram processos de desnacionalização ou, em número muito menor, de nacionalização.

A tabela 3 mostra que, de fato, as empresas estrangeiras são, em média, maiores e mais produtivas do que as empresas domésticas. Da mesma forma, seus trabalhadores parecem ter maior qualificação e os gastos em propaganda como proporção do faturamento também são maiores. Estas duas últimas variáveis são utilizadas, no estudo, respectivamente, como aproximações ao grau de tecnologia utilizado pela firma e para o grau de diferenciação de seu produto final. ${ }^{6}$

A análise desta tabela nos mostra que as empresas estrangeiras estão numa posição favorável em relação às nacionais em vários aspectos, $\mathrm{o}$ que lhes conferiria, ao menos potencialmente, maiores vantagens competitivas e potencial exportador do que as nacionais. Entretanto, a pequena diferença entre coeficientes de exportação dos dois grupos de firmas aliado a um substantivo diferencial nos coeficientes de importação, parece indicar que essas potenciais vantagens não se traduzem em um desempenho comercial efetivo mais favorável das empresas estrangeiras em relação às nacionais.

Para identificar o quanto a origem de capital, isolada das outras características da firma, influencia os fluxos de comércio das firmas individuais, o estudo estima equações de exportação e de importação,

5 Utilizaram-se informações provenientes do Censo de Capitais Estrangeiros do Bacen, de 1995 e de 2000; da Pesquisa Industrial Anual (PIA) do IBGE; da Secretaria de Comércio Exterior (SECEX); da Relação Anual de Informações Sociais (RAIS), do Ministério do Trabalho e da Pesquisa Nacional por Amostra de Domicílios (PNAD), também do IBGE.

6 Supõem-se que, a utilização mais intensiva de tecnologia exige maior qualificação da mão-de-obra que a opera. Da mesma forma, supõe-se que quanto maior é o esforço de vendas da empresa, representado pelos seus gastos em propaganda, maior será, em média, a diferenciação de produto desta empresa. 
Tabela 3 - INDICADORES SELECIONADOS PARA EMPRESAS NACIONAIS E ESTRANGEIRAS, EXPORTADORAS E NÃO EXPORTADORAS - MÉDIA DO PERÍODO 1996 A 2000.

\begin{tabular}{|c|c|c|c|c|c|c|c|c|c|c|}
\hline & & $\mathrm{N}$ & Part \% & $\begin{array}{c}\text { Fatura- } \\
\text { mento } \\
\text { (R\$ mil) }\end{array}$ & $\begin{array}{l}\text { Pessoal } \\
\text { ocupado }\end{array}$ & $\begin{array}{l}\text { Produti- } \\
\text { vidade* }\end{array}$ & $\begin{array}{l}\text { Tempo de } \\
\text { estudo do }\end{array}$ & $\begin{array}{l}\text { Gastos em } \\
\text { Propagan- } \\
\text { - }\end{array}$ & $\begin{array}{l}\text { Coef. } \\
\text { exp.(1) }\end{array}$ & $\begin{array}{l}\text { Coef. } \\
\text { imp.(1) }\end{array}$ \\
\hline चै & $\tilde{\text { n } \exp }$ & 42.186 & $78,30 \%$ & 4.316 & 62 & 69 & 6,7 & 0,53 & - & 0,101 \\
\hline 疍 & Exp & 9.436 & $17,50 \%$ & 45.406 & 298 & 144 & 7 & 0,81 & 0,159 & 0,071 \\
\hline 尹્च & Total & 51.622 & $95,80 \%$ & 11.853 & 105 & 83 & 6,7 & 0,61 & 0,159 & 0,086 \\
\hline & $\tilde{\mathbf{n}} \exp$ & 344 & $0,60 \%$ & 32.032 & 190 & 307 & 8,7 & 1,54 & - & 0,183 \\
\hline E & Exp & 1.894 & $3,50 \%$ & 161.575 & 636 & 382 & 9,1 & 1,34 & 0,165 & 0,162 \\
\hline 象 & Total & 2.238 & $4,20 \%$ & 136.479 & 549 & 368 & 9 & 1,38 & 0,165 & 0,165 \\
\hline TOTAL & & 53.860 & $100 \%$ & 18.176 & 128 & 97 & 6,9 & 0,67 & & \\
\hline
\end{tabular}

FONTE: De Negri (2003). *Produtividade do trabalho. Índice: média de 1996=100. ** Como porcentagem do faturamento. Gastos em propaganda se referem apenas a empresas com mais de 29 empregados. (1): Exportações/ importações em relação ao faturamento

utilizando-se dos micro-dados das empresas nos cinco anos da amostra. Os modelos estimados utilizaram técnicas de análise de dados em painel. Uma das vantagens dos modelos em painel sobre os modelos de regressão cross section é a sua capacidade de controlar a heterogeneidade existente entre os indivíduos através da estimação de efeitos individuais. ${ }^{7}$

As duas formulações mais comuns para especificar a natureza dos efeitos individuais em um modelo em painel são a utilização de efeitos fixos ou de efeitos aleatórios. A abordagem de efeitos fixos toma o efeito individual como sendo um termo constante específico a um grupo (ou indivíduo) no modelo de regressão. Por outro lado, a abordagem de efeitos aleatórios especifica que o efeito individual é um ruído específico de cada grupo, similar ao erro. No modelo de efeitos fixos, os efeitos individuais podem ser livremente correlacionados com os demais regressores enquanto que, no modelo de efeitos aleatórios, supõe-se que não há correlação entre efeitos individuais e demais variáveis explanatórias.

Para a estimação com efeitos fixos, o estimador de mínimos quadrados ordinários, chamado de LSDV (least squares dummy variable model), é um estimador consistente e eficiente do modelo. Para o modelo de efeitos aleatórios, utiliza-se o método dos mínimos quadrados generalizados,

7 Para detalhes sobre a metodologia utilizada, ver De Negri (2003). 
admitindo que os interceptos sejam independentemente e identicamente distribuídos. A definição de qual o modelo mais apropriado depende, em grande parte, de informações sobre as características da amostra e sobre os objetivos específicos da estimação. Existem, também, dois testes estatísticos comumente utilizados: o teste F para efeitos fixos e o teste de Hausman para efeitos aleatórios. ${ }^{8}$

As equações foram estimadas com informações sobre 7.606 empresas exportadoras, das quais 1534 estrangeiras, e com 9.054 empresas importadoras, entre as quais, 1659 estrangeiras, e são as seguintes:

$$
\begin{aligned}
& \operatorname{Ln}\left(X_{i t}\right)=\beta_{1} \operatorname{Ln}(\text { pess_ocup })_{i t}+\beta_{2} \operatorname{Ln}(\text { produtiv })_{i t}+\beta_{3} \operatorname{Ln}\left(t_{-} \text {empr }\right)_{i t} \\
& +\beta_{4} \operatorname{Ln}\left(t_{-} \text {est }\right)_{i t}+\beta_{5} \text { Ln }\left(i_{-} \text {gast_prop }\right)_{i t}+\beta_{6} \text { estrangeira }_{i}+\text { setor }_{i}+\text { ano } \\
& \operatorname{Ln}\left(M_{i t}\right)=\beta_{1} \operatorname{Ln}(\text { pess_ocup })_{i t}+\beta_{2} \operatorname{Ln}(\text { produtiv })_{i t}+\beta_{3} \operatorname{Ln}\left(t_{-} \text {empr }\right)_{i t} \\
& +\beta_{4} \operatorname{Ln}\left(t_{-} \text {est }\right)_{i t}+\beta_{5} \text { Ln }\left(i_{-} \text {gast_prop }\right)_{i t}+\beta_{6} \text { estrangeira }_{i}+\text { setor }_{i}+\text { ano } \\
& \operatorname{Ln}\left(i m p \_b i_{i t}\right)=\beta_{1} \operatorname{Ln}(\text { pess_ocup })_{i t}+\beta_{2} \operatorname{Ln}(\text { produtiv })_{i t}+\beta_{3} \operatorname{Ln}\left(t_{-} \text {empr }\right)_{i t} \\
& +\beta_{4} \operatorname{Ln}\left(t_{-} \text {est }\right)_{i t}+\beta_{5} \text { Ln }\left(i_{-} \text {gast_prop }\right)_{i t}+\beta_{6} \text { estrangeira }_{i}+\text { setor }_{i}+\text { ano }
\end{aligned}
$$

Onde:

1) $X_{i t}, M_{i t}, i m p \_b i_{i t}$ representam o valor das exportações, das importações e das importações de bens intermediários da firma;

2) pess_ocup it é o pessoal ocupado médio na empresa durante o ano, que irá captar a influência da escala de produção da firma no valor de suas exportações;

3) produtiv $v_{i t}$ é um indicador de produtividade da firma, calculado como o valor da transformação industrial em relação ao pessoal ocupado médio da empresa para cada um dos anos considerados;

$8 \quad$ O teste $\mathrm{F}$ testa a hipótese de que o termo constante seja igual para todos os grupos $\left(\alpha_{i}=\alpha_{j}\right.$ para $\left.\mathrm{i} \neq \mathrm{j}\right)$. A hipótese nula é, portanto, de que existe apenas um intercepto para todas as empresas. O segundo teste, realizado na estimação do modelo por efeitos aleatórios, é o teste de Hausman, que verifica a existência de correlação entre os efeitos individuais e as variáveis explanatórias. Se esta correlação não existe, o modelo de efeitos aleatórios é consistente e eficiente e o modelo de efeitos fixos é consistente mas não eficiente. No caso inverso, o estimador de efeitos fixos é consistente e eficiente mas o estimador de efeitos aleatórios é inconsistente. 
4) t_empr it é o tempo médio de emprego dos trabalhadores da firma, ou seja, a experiência dos seus trabalhadores. A baixa rotatividade da mãode-obra e a estabilidade organizacional numa empresa pode ser um indício de uma maior eficiência;

5) $t_{-} e s t_{i t}$ representa o tempo de estudo médio dos trabalhadores na firma, que procura medir a qualificação profissional destes trabalhadores;

6) t_gast_prop it é a variável que representa os gastos em propaganda da firma, em determinado ano, como proporção do seu faturamento.

7) estrangeira, variável binária que assume o valor zero para a empresa nacional e um para a empresa estrangeira. O parâmetro estimado para essa variável, quando significativo, dirá o quanto o fato de a empresa ser estrangeira influencia o valor das suas exportações.

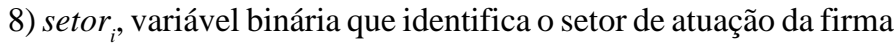
segundo a divisão de atividade da Classificação Nacional de Atividades Econômicas.

9) Por fim, a variável representa um conjunto de quatro binárias destinadas a captar a influência de cada ano nas exportações e importações da amostra.

Os resultados obtidos (tabela 4) mostram que a origem do capital da firma tem impactos maiores sobre suas importações do que sobre suas exportações.

No modelo de efeitos fixos, as empresas estrangeiras importam, em média $26 \%$ a mais do que as nacionais, enquanto não apresentam diferenças em termos de exportações. Estes resultados são compatíveis com aqueles obtidos em Chudnovsky et al. (2002). Por outro lado, no modelo de efeitos aleatórios, a origem de capital é um fator significativo para explicar as diferenças entre as firmas, tanto pelo lado das importações quanto das exportações, entretanto, essa diferença é sensivelmente maior nas importações. Enquanto as empresas estrangeiras exportam, em média, $70 \%$ a mais do que as empresas nacionais, elas importam cerca de $290 \%$ a mais.

Os resultados obtidos sugerem que o impacto imediato da desnacionalização - captado pelo modelo de efeitos fixos - é o aumento das importações das firmas recém desnacionalizadas. Esta, portanto, é a única modificação relevante no comportamento comercial das firmas que pôde ser observada no curto prazo.

Por outro lado, podemos considerar o modelo de efeitos aleatórios como uma melhor aproximação da diferença entre empresas estrangeiras e nacionais em um prazo de tempo mais longo. Nesse sentido, possíveis diferenças no acesso a mercados externos, na organização produtiva, entre outros, estariam agora refletidas no coeficiente da dummy. Assim, empresas 
estrangeiras no mesmo setor, com o mesmo tamanho em termos de números de funcionários, com indicadores de produtividade, tecnologia e diferenciação de produto semelhantes, tendem a exportar e importar mais do que empresas nacionais.

Tabela 4 - RESULTADOS DA ESTIMAÇÃO DE EQUAÇÕES DE EXPORTAÇÃO, DE IMPORTAÇÃO E DE IMPORTAÇÃO DE BENS INTERMEDIÁRIOS PARAAS FIRMAS DA INDÚSTRIA DE TRANSFORMAÇÃO BRASILEIRA NO PERÍODO 1996-2000.

\begin{tabular}{|c|c|c|c|c|c|c|}
\hline \multicolumn{7}{|c|}{ EFEITOS FIXOS } \\
\hline \multirow[t]{2}{*}{ Variáveis } & \multicolumn{2}{|c|}{ Exportações } & \multicolumn{2}{|c|}{ Importações (1) } & \multicolumn{2}{|c|}{$\begin{array}{c}\text { Importações de Bens } \\
\text { Intermediários }\end{array}$} \\
\hline & Estimativa & teste $\mathrm{t}$ & estimativa & teste $\mathrm{t}$ & Estimativa & teste $\mathrm{t}$ \\
\hline Pess_ocup & 0,637 & 23,890 & 0,542 & 16,400 & 0,618 & 22,280 \\
\hline Produtiv & 0,085 & 9,540 & 0,054 & 6,320 & 0,043 & 5,760 \\
\hline Estrangeira & NS & NS & 0,235 & 2,090 & 0,153 & 2,890 \\
\hline t_empr & NS & NS & NS & NS & NS & NS \\
\hline t_est & NS & NS & NS & NS & 0,127 & 2,110 \\
\hline i_gast_prop & $-0,015$ & $-2,110$ & 0,022 & 2,510 & NS & NS \\
\hline $\mathrm{R} 2$ & 0,996 & & 0,996 & & 0,998 & \\
\hline Valor de F & 13,81 & & 11,22 & & 11,48 & \\
\hline$\underline{\mathrm{N}}$ & 5638 & & 6104 & & 4680 & \\
\hline \multicolumn{7}{|c|}{ EFEITOS ALEATÓRIOS } \\
\hline \multirow[t]{2}{*}{ Variáveis } & \multicolumn{2}{|c|}{ Exportações } & \multicolumn{2}{|c|}{ Importações (1) } & \multicolumn{2}{|c|}{$\begin{array}{c}\text { Importações de Bens } \\
\text { Intermediários }\end{array}$} \\
\hline & estimativa & teste $\mathrm{t}$ & estimativa & teste $\mathrm{t}$ & Estimativa & teste $\mathrm{t}$ \\
\hline Intercepto & 6,783 & 36,680 & 6,183 & 32,300 & 7,845 & 46,760 \\
\hline pess_ocup & 0,927 & 51,530 & 0,801 & 44,160 & 0,836 & 49,440 \\
\hline Produtiv & 0,124 & 14,860 & 0,096 & 12,500 & 0,082 & 11,820 \\
\hline Estrangeira & 0,530 & 11,660 & 1,355 & 24,570 & 0,625 & 15,650 \\
\hline t_empr & 0,093 & 4,620 & 0,075 & 3,590 & 0,072 & 3,950 \\
\hline t_est & 0,168 & 2,990 & 0,812 & 11,820 & 0,498 & 9,460 \\
\hline i_gast_prop & $-0,053$ & $-8,000$ & 0,021 & 2,910 & NS & NS \\
\hline $\mathrm{R} 2$ & 0,160 & & 0,203 & & 0,191 & \\
\hline $\begin{array}{l}\text { Hausman (valor de } \\
\text { m) }\end{array}$ & 679,20 & & 497,130 & & 550,73 & \\
\hline $\mathrm{N}$ & 5638 & & 6104 & & 4679 & \\
\hline
\end{tabular}

FONTE: De Negri (2003). Obs.: NS: Variável não significativa a 10\%. (1) Equação estimada para o período 1997-2000. Além das variáveis apresentadas, também foram estimadas dummies para o setor de atuação da empresa e para o ano. 


\section{CONSIDERAÇõES FINAIS}

O balanço do debate a respeito do impacto de uma maior internacionalização produtiva sobre os fluxos de comércio brasileiro, bem como as evidências recentes proporcionam um olhar mais realista sobre a possibilidade efetiva de contribuição das empresas estrangeiras à melhoria quantitativa e qualitativa da balança comercial brasileira. Não parece possível, a partir destas evidências, admitir a hipótese de que a maior presença estrangeira na estrutura produtiva brasileira traduza, por si mesma, um resultado comercial mais favorável ao país. São muitas as razões para tal, muito embora as empresas transnacionais sejam, de fato, mais integradas ao comércio mundial do que as empresas domésticas.

A possibilidade de contar com filiais em vários países do mundo proporciona às ETS maior acesso a estes mercados, além de uma série de outras vantagens: economias de escala advindas da maior especialização de suas filiais; acesso facilitado à crédito e a novas tecnologias, entre outras. Estas diferenças ocasionam, efetivamente, comportamentos comerciais diferenciados das empresas "uninacionais". Vários resultados apresentados no debate mostram o quanto estas diferenças importam em termos de comércio, a ponto de sobrepujar o efeito de outros fatores tradicionalmente ligados à competitividade internacional.

Entretanto, o que as evidências mostram é que as potenciais vantagens competitivas das ETS não se traduziram, neste período, em um desempenho comercial favorável, tampouco em vantagens competitivas para o país. Essa transposição dependeria, em grande medida, das estratégias comerciais e financeiras das empresas estrangeiras, influenciadas pelos sinais gerados pela política econômica. Justamente em função do seu maior acesso aos mercados externos, as ETS possuem uma capacidade de resposta maior aos sinais macroeconômicos, particularmente aqueles relacionados à taxa de câmbio. Explica-se assim, que no período de forte valorização do Real tenham aumentado proporcionalmente mais suas importações do que as exportações e contribuído para o resultado negativo da balança comercial, contrariamente ao que os defensores ingênuos da abertura e da desnacionalização esperavam.

Por outro lado, a experiência dos últimos anos mostra que da mesma forma que o acesso a mercados dessas empresas pode significar uma ampliação do acesso do país aos mercados externos, também pode atuar no sentido inverso. Assim, a existência de fornecedores já estabelecidos em nível mundial pode estar desempenhando um papel mais relevante nas importações das empresas estrangeiras do que em suas exportações. O acesso a canais de 
comercialização poderia estar atuando no sentido inverso do esperado, ou seja, ao invés de estar ampliando as exportações brasileiras, estaria contribuindo para um aumento de suas importações, como efetivamente ocorreu até recentemente.

É claro que não se deve desconsiderar o fato de que, durante a maior parte da última década, tanto empresas estrangeiras quanto nacionais apresentaram expressivos déficits comerciais. Em um regime macroeconômico mais propício às exportações, a maior sensibilidade de resposta das empresas estrangeiras poderia contribuir para uma elevação mais rápida de suas exportações. Entretanto, as empresas transnacionais constituem um segmento diferenciado dentro da estrutura industrial brasileira, com padrões de comportamento comercial também diferenciados e sujeitos a determinantes diversos daqueles que afetam as empresas domésticas. Dessa forma, as características dos investimentos estrangeiros no Brasil também deveriam ser levadas em consideração na formulação de políticas industriais ou comerciais sob pena de não se alcançar os objetivos macroeconômicos desejados.

\section{RESUMO}

Durante os anos 90, vários autores procuraram avaliar os impactos do processo de internacionalização produtiva da economia brasileira sobre o seu desempenho externo. Este trabalho procura reproduzir e avaliar as evidências levantadas por esses autores durante a década e, por meio de uma análise de dados em painel, acrescentar novos elementos ao debate. A pergunta a ser respondida é se a origem de capital da firma (estrangeira ou nacional) é um determinante importante de suas exportações e importações. Para isso, utilizaram-se microdados das empresas industriais brasileiras no período de 1996 a 2000 e controlaram-se outros fatores capazes de influenciar o desempenho comercial das firmas. Os resultados obtidos apontam para uma maior inserção comercial das empresas estrangeiras instaladas no país em relação às firmas domésticas, sendo esta maior inserção significativa e maior nas importações do que nas exportações. Estes resultados contradizem as expectativas iniciais de alguns autores de que as empresas estrangeiras pudessem estar colaborando para um desempenho comercial mais favorável ao país durante a década.

Palavras-chave: investimento direto externo, empresas transnacionais, comércio exterior brasileiro. 


\begin{abstract}
During the nineties some economists expected that the intense process of productive internationalization of the Brazilian economy would bring gains, particularly regarding to the trade performance of the country. This paper aims at evaluating the importance of the ownership - foreign or national - as a determinant of trade of the industrial firms in Brazil between 1996 and 2000. The analysis used individual information about more than 50.000 industrial companies in the period into a panel data econometric model. The results show that transnational corporations seem to be more integrated into international trade than locally owned firms. However, this larger integration takes the form, essentially, of stronger import activities more than of larger exports. These results contradict the expectations of some economists: that foreign companies could collaborate for a better Brazilian trade performance during the period.

Key-words: foreign direct investment, transnational corporations, foreign trade.
\end{abstract}

\title{
REFERÊNCIAS
}

ARBACHE, J.; DE NEGRI, J. A. Determinantes das exportações brasileiras: novas evidências. 2001. Mimeografado.

BARROS, J. R. M.; GOLDENSTEIN, L. Reestruturação industrial: três anos de debate. In: VELLOSO (Org.). Brasil: desafios de um país em transformação. Rio de Janeiro: José Olympio, 1997.

BIELSCHOWSKY, R.; STUMPO, G. A internacionalização da indústria brasileira: números e reflexões depois de alguns anos de abertura. In: BAUMANN, R. (Org.). O Brasil e a economia global. Rio de Janeiro: Campus: Sobeet, 1996.

BONELLI, R. A note on foreign direct investment (FDI) and industrial competitiveness in Brazil. Rio de Janeiro: Ipea, 1998. Discussão, n. 584.

CEPAL. La inversión extranjera en América Latina y Caribe: informe 1998. Cepal, 1998.

CHUDNOVSKY, D. (Org.). Integración regional e Inversión Extranjera Directa: El caso del Mercosur. Buenos Aires: BID - Intal, 2002.

DE NEGRI, F. Desempenho comercial das empresas estrangeiras no Brasil na década de 90. Campinas, 2003. Dissertação (Mestrado em Economia) - IE-Unicamp. Mimeografado. 
FRITSCH, W.; FRANCO, G. H. B. O investimento direto estrangeiro em uma nova estratégia industrial. Revista de Economia Política, v. 9, n. 2, abr./jun. 1989.

HIRATUKA, C. Empresas transnacionais e comércio exterior: uma análise das estratégias das filiais brasileiras no contexto da abertura econômica. Campinas, 2002. Tese (Doutorado em Economia) - IE-Unicamp.

LACERDA, A. C. (Org.). Desnacionalização: mitos, riscos e desafios. São Paulo: Contexto:, 2000.

LAPLANE, M.; SARTI, F. Investimento direto estrangeiro e a retomada do crescimento sustentado nos anos 90. Economia e Sociedade, Campinas, n. 8, jun. 1997.

. Investimento direto estrangeiro e o impacto na balança comercial nos anos 90. Brasília: Ipea, fev. 1999. Discussão, n. 629.

LAPLANE, M. et al. Internacionalização e vulnerabilidade externa. In: LACERDA, A. C. (Org.). Desnacionalização: mitos, riscos e desafios. São Paulo: Contexto, 2000.

MOREIRA, M. M. A indústria brasileira nos anos 90: o que já se pode dizer?. In: GIAMBIAGI (Org.). A economia brasileira nos anos 90. Rio de Janeiro: BNDES, s.d.

. Capital nacional na indústria: reestruturar para sobreviver. In: LACERDA, A. C. (Org.). Desnacionalização: mitos, riscos e desafios. São Paulo: Contexto, 2000.

. Estrangeiros em uma economia aberta: impactos recentes sobre produtividade, concentração e comércio exterior. Rio de Janeiro: BNDES, mar. 1999. Discussão, n. 67. 